\title{
ANALISIS IMPLEMENTASI PROGRAM PEMBINAAN TERPADU PENYAKIT TIDAK MENULAR (POSBINDU PTM) DENGAN MENGGUNAKAN TEORI WLLIAM C EDWARD DI PUSKESMAS KAMPUNG BARU TAHUN 2020
}

\author{
Analysis of the Implementation of the Integrated Non-Communicable \\ Diseases Development Program (POSBINDU PTM) using William C \\ Edward's Theory at Kampung Baru Community Health Center 2020
}

\author{
Dewi Rismauli Bancin*1, Idaria Sidabukke ${ }^{2}$ \\ 1,2, Universitas Sari Mutiara Indonesia, Jalan Kapten Muslim No 79, Medan, Indonesia \\ dewi_bancin@ymail.com ${ }^{1}$; Ridaria@yahoo.com; ${ }^{2}$
}

\begin{abstract}
Abstrak
Saat ini Puskesmas Kampung Baru, masih melaksanaan Posbindu PTM dan sudah tepat sasaran dapat dilihat dari data kunjungan Posbindu PTM yang dilaksanakan, tetapi masih ada masarakat yang tidak dapat hadir dikarenakan masalah informasi yang diberikan petugas kurang konsisten dalam segi waktu dan dapat diperhitungkan kehadiran masyarakat dalam mengikuti program Posbindu PTM hanya 65\%. Tujuan dari penelitian ini adalah menganalisis pelaksanaan program Posbindu PTM di Puskesmas Kampung Baru, Kota Medan. Jenis penelitian yang dilakukan merupakan penelitian kualitatif dengan studi kasus (case study) melalui wawancara mendalam. Penelitian ini dilakukan pada bulan agustus 2020. Hasil penelitian ini menunjukkan bahwa pelaksanaan Posbindu PTM di Puskesmas Kampung Baru Medan belum berjalan dengan optimal. Dilihat dari variabel komunikasi, Komunikasi sudah diberikan kepada seluruh sasaran program dan masih terdapat informasi yang salah, sehingga pemahaman masyarakat akan sasaran Posbindu PTM kurang tepat. Sumber daya manusia dalam implementasi program Posbindu PTM sudah sesuai dengan kebutuhan hanya saja masih membutuhkan arahan agar lebih baik lagi dala melaksanakan program Posbindu PTM, Fasilitas yang disediakan untuk pelaksanaan program Posbindu PTM masih kurang mencukupi, Sikap dari pelaksana program Posbindu PTM sudah baik dan sudah mendukung pelaksanaan program Posbindu PTM dapat dilihat dari pelaksanaan program Posbindu PTM setiap bulannya selalu melaksanakan program Posbindu PTM, terkait SOP dalam pelaksanaan Posbindu PTM sudah dijalankan dan pembagian tugas dan tanggungjawab dalam pelaksanaan program Posbindu PTM sesuai dengan bidangnya masing-masing.
\end{abstract}

Kata Kunci : Implementasi, Pembinaan, POSBINDU

\section{Abstract}

At present the Kampung Baru Puskesmas is still implementing Posbindu PTM and it has been right on target. It can be seen from the data on the Posbindu PTM visit that was carried out, but there are still people who cannot attend because the information problem provided by officers is not consistent in terms of time and can be calculated by the presence of the community in following PTM Posbindu program only 65\%. The purpose of this study was to analyze the implementation of the PTM Posbindu program at the Kampung Baru Community 
Journal of Healthcare Technology and Medicine Vol. 6 No. 2 Oktober 2020

Universitas Ubudiyah Indonesia

e-ISSN : 2615-109X

Health Center, Medan City. This type of research is a qualitative research with a case study (case study) through in-depth interviews. This research was conducted in August 2020. The results of this study indicate that the implementation of Posbindu PTM at Kampung Baru Medan Health Center has not been running optimally. Judging from the communication variable, communication has been given to all program targets and there is still wrong information, so that people's understanding of the targets of Posbindu PTM is not quite right. Human resources in implementing the Posbindu PTM program are in accordance with the needs, it's just that they still need direction to be better at implementing the Posbindu PTM program, the facilities provided for the implementation of the PTM Posbindu program are still insufficient, The attitude of the implementers of the PTM Posbindu program is good and already supportive the implementation of the Posbindu PTM program can be seen from the implementation of the Posbindu PTM program every month always carrying out the Posbindu PTM program, related to the SOP in the implementation of the PTM Posbindu has been carried out and the division of duties and responsibilities in the implementation of the PTM Posbindu program according to their respective fields

\section{Keywords: Implementation, Development, POSBINDU}

\section{PENDAHULUAN}

Penyakit Tidak Menular (PTM) saat ini menjadi penyebab utama kematian di dunia. Dua dari sepuluh penyebab utama kematian di dunia disebabkan oleh penyakit tidak menular seperti stroke dan penyakit jantung bahkan menjadi penyebab teratas di Negara maju maupun Negara berkembang. Ada 57 juta kematian yang terjadi di dunia pada tahun 2008, sebanyak 36 juta atau 63\% disebabkan oleh PTM, terutama disebabkan oleh penyakit kardiovaskuler (48\%), diabetes mellitus (3\%), kanker (21\%). Menurut perkiraan WHO, kematian akibat PTM akan meningkat 15\% secara global (sebanyak 44 juta kematian) antara tahun 2010-2030. Wilayah yang akan mengalami peningkatan paling besar sebesar lebih dari $20 \%$ terjadi di wilayah Afrika, Asia Tenggara dan Mediterania Timur. Seluruh kematian akibat PTM terjadi pada orang berusia kurang dari 60 tahun, 29\% di Negara berkembang, sedangkan di Negara maju sebesar $13 \%$.

Hasil Riset Kesehatan Dasar (Riskesdas) tahun 2007 dan 2013 melaporkan bahwa prevalensi PTM cenderung meningkat seperti hipertensi, diabetes mellitus, stroke dan penyakit sendi. Fenomena ini diprediksi akan terus berlanjut. Data Riskesdas tahun 2013 menunjukkan secara nasional prevalensi hipertensi yang diperoleh melalui pengukuran sebesar 25,8\%. Data Survei Indikator Kesehatan Nasional (Sirkesnas) tahun 2016, prevalensi hipertensi mengalami peningkatan menjadi sebesar $30,9 \%$. Ini berarti hanya $1 / 3$ yang terdiagnosis, sisanya $2 / 3$ tidak terdiagnosis. Sebagian besar penderita hipertensi tidak menyadari penderita hipertensi. Hal 
Journal of Healthcare Technology and Medicine Vol. 6 No. 2 Oktober 2020

Universitas Ubudiyah Indonesia

e-ISSN : 2615-109X

yang sama untuk prevalensi stroke juga meningkat dari 8,3 per 1000 pada tahun 2007 menjadi 12,1 per 1000 pada tahun 2013. Begitu juga prevalensi diabetes mellitus mengalami peningkatan dari 1,1\% pada tahun 2007 menjadi 2,1\% pada tahun 2013. (Primiyani, 2018)

Salah satu program pemberdayaan masyarakat dalam upaya pencegahan dan deteksi dini PTM adalah Pos Pembinaan Terpadu (Posbindu) Penyakit Tidak Menular (PTM). Posbindu PTM merupakan salah satu bentuk upaya kesehatan dalam pengendalian faktor resiko PTM yang berada dibawah pembinaan puskesmas. Puskesmas Kampung Baru melaksanakan kegiatan dari program penatalaksanaan Penyakit Tidak Menular (PTM), yaitu Posbindu (Pos Pembinaan Terpadu), yaitu setiap bulan dilakukan pemeriksaan kesehatan di enam kelurahan yaitu Kampung Baru, Sei Mati, Aur, Kelurahan Sukaraja, Hamdan dan Jati. Pemeriksaan PTM meliputi pemeriksaan Kadar Gula Darah (KGD), Tekanan Darah, Indeks Masa Tubuh (IMT), dan dilakukan pada semua warga yang berusia diatas 15 tahun. Posbindu PTM dilaksanakan secara terpadu dan rutin setiap bulannya dan dilaksanakan di kelurahan yang ditetapkan oleh pihak Puskesmas Kampung Baru. Berdasarkan pelaksanaan program Posbindu PTM di Puskesmas Kampung Baru ditemukan kasus Penyakit Tidak Menular (PTM) terjadi peningkatan dari tahun 2018-2019, seperti hipertensi. Dimana penyakit hipertensi di kelurahan Sukaraja dan Kelurahan Aur meningkat. Pada tahun 2018, di kelurahan Sukaraja kasus hipertensi laki-laki sebanyak 78 orang dan perempuan sebanyak 59 orang, sedangkan pada tahun 2019 dikelurahan Sukaraja kasus hipertensi laki-laki sebanyak 80 orang dan perempuan sebanyak 59 orang. sedangkan di kelurahan Aur pada tahun 2018, terdapat kasus hipertensi laki-laki 68 orang dan perempuan sebanyak 60 orang. Dan pada tahun 2019 jumlah kasus hipertensi di kelurahan Aur laki-laki sebanyak 72 orang dan perempuan 64 orang. (Laporan Tahunan Kp. Baru, 2019)

Penyakit tidak menular muncul dari kombinasi faktor risiko yang tidak dapat dimodifikasi dan faktor risiko yang dapat dimodifikasi. Faktor risiko yang tidak dapat dimodifikasi atau diubah adalah usia, jenis kelamin, dan genetika. Sedangkan faktor risiko yang dapat dimodifikasi adalah faktor yang dapat diubah melalui kesadaran individu itu sendiri. Faktor-faktor yang dapat diubah tersebut adalah perilaku merokok, konsumsi minuman beralkohol, pola makan yang buruk, kurangnya aktivitas fisik. Untuk pengukuran dan pemeriksaan faktor risiko PTM dilakukan tindak lanjut berupa pembinaan secara terpadu dengan peningkatan pengetahuan dan kemampuan masyarakat tentang cara mengendalikan faktor risiko PTM melalui penyuluhan secara massal, konseling, hingga rujukan apabila 
Journal of Healthcare Technology and Medicine Vol. 6 No. 2 Oktober 2020

Universitas Ubudiyah Indonesia

e-ISSN : 2615-109X

diperlukan. Adapun 3 penyakit dalam kegiatan Posbindu PTM yang ditangani oleh pihak puskesmas, yaitu obesitas, diabetes mellitus, dan hipertensi.(Efrida et al., 2016)

Melihat pentingnya memelihara kesehatan, maka Puskesmas Kampung Baru melaksanakan program Posbindu PTM di 6 kelurahan disetiap bulannya tujuannya agar tercipta kebiasaan hidup sehat pada kalangan masyarakat. Untuk melaksanakan program Posbindu PTM pihak puskesmas memberikan tugas kepada tenaga kesehatan yang berkompeten dalam bidangnya, yaitu tenaga kesehatan dari keperawatan dan kesehatan masyarakat dibidang promosi kesehatan dan ditambah kader disetiap kelurahan untuk melaksanakan program Posbindu PTM. Penulis sudah melakukan wawancara kepada informan yang ditentukan. Peneliti menemukan pernyataan dari masyarakat setempat, bahwa program Posbindu PTM benar dilakukan setiap bulannya, namun didalam pelaksanaannya jadwal pertemuan sering mundur dan penyuluhan yang disampaikan hanya secara umum saja. Bahkan penduduk yang menghadiri, tidak sesuai dengan jumlah yang diharapkan (yang hadir hanya sedikit), dalam hal ini ada yang kurang dalam pelaksanaan program Posbindu PTM sehingga penulis tertarik untuk melakukan penelitian terkait keberhasilan program Posbindu PTM dengan judul " Analisis implementasi program pos pembinaan terpadu penyakit tidak menular (Posbindu PTM) dengan menggunakan teori William C. Edward di Puskesmas Kp. Baru tahun 2020”.(Putri et al., 2018)

\section{METODE PENELITIAN}

Jenis penelitian ini menggunakan penelitian kualitatif, Penelitian kualitatif adalah penelitian yang bersifat deskriptif dan cenderung menggunakan analisis. Jenis penelitian ini menggunakan metode studi kasus (case study) yang bertujuan untuk mengetahui lebih mendalam dan jelas tentang program Posbindu PTM di Puskesmas Kmapung Baru. Landasan teori dimanfaatkan sebagai pemandu agar fokus penelitian sesuai fakta dilapangan.(Rahmat, 2009). Informan dalam penelitian ini sejumlah 7 orang yang terdiri dari :

1. 1 informan kepala puskesmas,

2. 1 informan petugas puskesmas yang terkait dalam program Posbindu PTM,

3. 2 informan kader Posbindu PTM,

4. 1 informan tokoh masyarakat,

5. 2 informan dari kelompok sasaran Posbindu PTM.

\section{HASIL DAN PEMBAHASAN}

\section{Peran Komunikasi Dalam Implementasi Program Posbindu PTM}


Journal of Healthcare Technology and Medicine Vol. 6 No. 2 Oktober 2020

Universitas Ubudiyah Indonesia

e-ISSN : 2615-109X

Berdasarkan informasi dari hasil wawancara via chat wa dengan petugas Posbindu PTM yaitu seorang perawat di Puskesmas Kampung Baru menyatakan bahwa melakukan penyampain informasi terkait program Posbindu PTM ini dengan penyuluhan. Berikut narasi dengan perawat (Penanggungjawab Posbindu PTM) tersebut :

“Hmm...kami hanya sosialisasi saja pas pertemuan dilintas sektorat gitu, iya pada saat pertemuan kan banyak nih yang kita undang salah satunya masyarakat, kaderkader, tokoh masyarakat, dan lain-lain. Dipertemuan tersebut kita menjelaskan terkait dengan program Posbindu PTM yang akan kita laksanakan. Soal informasi yang kita sampaikan sudah begitu jelas, dapat kita lihat dari kehadiran masyarakat yang mau ikut serta dalam pelaksanaan program Posbindu PTM. Dan cara lain kami juga ada sih, 3 hari sebelum pelaksanaan program Posbindu PTM kami menginformasikan kepada kader agar mengingatkan kembali kepada masayarakat bahwa 3 hari lagi akan dilaksanakan program Posbindu PTM”.

Berdasarkan informasi yang didapat melalui wawancara via telfon dengan kader kelurahan Aur dengan Ibu Mimi menyatakan bahwa penyampain informasi sama dengan apa yang disampaikan oleh penanggungjawab program Posbindu PTM, berikut narasi dari kader tersebut

“ iya kalo kami sih selalu mengingatkan kembali sebelum pelaksanaan program Posbindu PTM dilaksanakan kami kader-kader selalu mendatangi kerumah-rumah masyarakat untuk mengingatkan kembali kapan akan dilaksankan program Posbindu PTM”.

Dan narasi dari Ibu Melu selaku kader dari kelurahan Sukaraja tersaji dibawah ini :

“ Hmm, iya kita informasikan kerumah warga mau ada program Posbindu PTM yang akan dilaksanakan, dan kita kasih tau apasaja yang ada dalam pelaksanaan program Posbindu PTM, salah satu contohnya pengukuran gula darah gitulah biar mereka paham”.

Berikut hasil dari Tokoh masyarakat dikelurahan Aur, yaitu Bapak Hapri Tanjung yang setiap bulan rutin mengikuti program Posbindu PTM, namun masih ada kendala dalam tidak konsistennya dalam segi waktu, berikut narasinya :

“ Iya, Posbindu itu kan 1 bulan sekali 5 hari atau 1 minggu sebelum pelaksanaan itu sudah diumumkan melalui grup wa, karena kan program Posbindu PTM ini selalu nya berganti tempatnya jadi harus selalu dikabarin memalui chat wa dan 
Journal of Healthcare Technology and Medicine Vol. 6 No. 2 Oktober 2020

Universitas Ubudiyah Indonesia

e-ISSN : 2615-109X

saya pribadi merasa pesan yang disampaikan melalui grup wa kadang tidak sesuai terlambat 5-10 menit itu sih wajar menurut saya”.

Berikut hasil wawancara saya dengan masyarakat dari kelurahan Aur yang rutin mengikuti program Posbindu PTM, yaitu dengan Ibu Ayuk. Berikut narasai Ibu Ayuk terkait informasi yang didapat dalam pelaksanaan program Posbindu PTM :

“ Hmmm kita kan setiap 1 bulan sekali tuhh mengikuti Posbindu PTM jadi petugasnya datang kerumah gitu dan kebetulan ditempat ibu keseringan dilaksanakan jadi kadang kerumah ibu memberitahukan kadang saya baca dari wa saja sihh dek....penyampain pesan dari petugas saya rasa sudah cukup baik sihh mengenai pemeriksaan kesehatan gitu setiap bulannya, jadi kita tahu dong memantau kesehatan dan menjaga agar kita tetap sehat, itu saja sihh...".

Adapun hasil wawancara saya dengan Ibu Riri masyarakat dari kelurahan Sukaraja yang tidak rutin mengikuti program Posbindu PTM, berikut narasinya :

“ Kalo saya dek informasi yang saya dapat itu, iya baik sih sejauh ini penyuluhan yang kadang saya ikutin pun menarik dek, hanya saja saya kadang tidak mengikuti dek karena kerjaan saya dan pelaksanaan program Posbindu PTM ini bersamaan, jadi itu yang buat saya tidak dapat mengikutinya, kalo soalnya informasi yang petugas berikan baik dengan cara mendatangi kerumah-rumah warga menceritakan sedikit kegunaan dan manfaat mengikuti program Posbindu PTM ini”.

Berikut hasil wawancara terakhir dengan Ibu Erwina selaku Kepala Puskesmas di Puskesmas Kampung Baru, adapun narasi Ibu Erwina sebagai berikut :

“ Hmm.. penyuluhan tentu pasti melalui penyuluhan kita undang masyarakat ada pertemuan kemudian di Posbindu setiap ada pertemuan lintas sektoral kita infokan, seperti itu”. Penyampain informasi menurut saya saya jelas”.

Peran komunikasi dalam pelaksanaan program Posbindu PTM yang dilakukan dengan tatap muka langsung dengan kelompok sasaran sehingga lebih mudah untuk memahaminya. Pelaksaanan program Posbindu PTM sangat bermanfaat bagi kelompok sasaran. Keberhasilan komunikasi dapat dilihat dari pelaksanaan program Posbindu PTM yang dilaksanakan setiap 1 bulan sekali dengan rutin. Penyampaian komunikasi yang disampaikan oleh petugas kepada kelompok sasaan sudah baik dapat dilihat kehadiran kelompok sasaran yang datang dalam pelaksanaan program Posbindu PTM. Kejelasan komunikasi berupa sosialisasi dan penyuluhan 
Journal of Healthcare Technology and Medicine Vol. 6 No. 2 Oktober 2020

Universitas Ubudiyah Indonesia

e-ISSN : 2615-109X

sudah diterapkan dalam pelaksanaan program Posbindu PTM yang diberikan kepada kelompok sasaran.

Namun dalam pelaksanaan program Posbindu PTM perlu diperhatikan, salah satunya komunikasi. Dimana komunikasi merupakan salah satu cara untuk memberikan dukungan untuk pelaksanaan program Posbsindu PTM. Indikator keberhasilan komunikasi dapat dilihat dari 3 (tiga) indikator, salah satunya adalah transmisi, kejelasan pesan dan juga konsisten waktu. Penelitian yang dilaksanakan di Puskesmas Kampung Baru belum mendukung dikarenakan masih adanya ketidakkonsistenan waktu petugas dan masyarakat dalam pelaksanaan program Posbindu PTM. Salah satu contoh ketidakkonsistenan waktu oleh petugas adalah kehadiran yang tidak tepat dalam pelaksanaan program Posbindu PTM.

Penelitian sebelumnya ukuran dan tujuan kebijakan berhubungan dengan bagaimana tingkat keberhasilan suatu program tersebut dapat dicapai, karena keberhasilan suatu program merupakan salah satu indikator yang dapat dijadikan pedoman kebijakan tersebut dapat dilanjutkan atau memerlukan evaluasi lebih lanjut untuk diperbaiki. Pada variabel komunikasi, penyaluran komunikasi berupa sosialisasi posbindu PTM yang diberikan secara langsung tatap muka oleh pelaksanaan puskesmas pucang sewu sudah baik, namun sosialisasi yang diberikan masih belum merata. Kejelasan komunikasi terkait program Posbindu sudah baik, sebelum terjun ke lapangan para pelaksana dibekali dengan pelatihan dan bimbingan teknis. Pedoman yang digunakan dalam melaksanakan kebijakan juga konsisten. Dalam melakukan penyuluhan, materi yang diberikan di setiap pertemuan posbindu PTM juga konsisten. (Febrianti et al., 2016)

\section{Peran Struktur Sosial/Sumber Daya Dalam Implementasi Program Posbindu PTM}

Berdasarkan informasi dari hasil wawancara via chat wa dengan petugas Posbindu PTM yaitu seorang perawat di Puskesmas Kampung Baru menyatakan bahwa SDM dalam pelaksanaan program Posbindu PTM ini sudah baik tetapi masih perlu peningkatan. Berikut narasi dengan perawat (Penanggungjawab Posbindu PTM) tersebut :

“Ya menurut saya SDM untuk pelaksanaan program Posbindu PTM ini sudah cukup, dimana ada kader 5 orang, ada juga Dokter, dan ada juga bagian promosi kesehatan. Pelaksanaan tugas dan keterampilan SDM sudah cukup baik hanya saja perlu peningkatan lagi. Fasilitas berupa gedung untuk pelaksanaan masih belum menetap”. Untuk pelatihan sudah diberikan kepada setiap kader-kader kesehatan berupa buku pintar dan lain-lain”. 
Journal of Healthcare Technology and Medicine Vol. 6 No. 2 Oktober 2020

Universitas Ubudiyah Indonesia

e-ISSN : 2615-109X

Berdasarkan informasi yang didapat melalui wawancara via telfon dengan kader kelurahan Aur dengan Ibu Mimi menyatakan bahwa SDM dalam pelaksanaan program Posbindu PTM sama dengan apa yang disampaikan oleh penanggungjawab program Posbindu PTM, berikut narasi dari kader tersebut :

“Sudah mencukupi, ada 5 orang dibantu dengan petugas yang dari puskesmas juga, kami dikasih pelatihan berupa penyuluhan dan juga berupa buku panduan”.

“ Kita kan banyak jadi setiap sebulan sekali itu selalu bergantian tugasnya tidak monoton disatu meja saja, itu kami buat kebijakan sendii karena kami juga pengen tahu di semua meja itu apa saja yang diperiksa, dan masalah wewenang dan kemampuan kami sudah kami buat sebaik mungkin dalam pelaksanaan program Posbindu PTM ini”.

Dan narasi dari Ibu Melu selaku kader dari kelurahan Sukaraja tersaji dibawah ini :

“ Ohhh.. kalo kadernya sudah cukuplah 5 orang semua bekerja ada yang mengukur tinggi, berat badan, lingkar perut, kadar gula darah, dan lain-lain. Wewenang dalam SDM itu sudah semua menerapkan hanya saja masih kurang peningkatan agar lebih baik lagi, wewenang saya dibagian meja 2 yaitu memegang alat untuk mengukur pendeteksi kadar lemak jantung”.

“ Untuk fasilitas gedung masih sering dibicarak kepada masyarakat, siapa masyarakat yang bersedia dirumahnya pelaksanaan program Posbindu PTM dilaksanakan, kalo masyarakat tidak bersedia kita menyerahkannya kepada kepling agar supaya kepling yang mencari tempat untuk pelaksanaan program Posbindu PTM tersebut".

Berikut narasi dari Tokoh masyarakat dikelurahan Aur, yaitu Bapak Hapri Tanjung yang setiap bulan rutin mengikuti program Posbindu PTM :

“ Iya kalo saya priibadi pas mengikuti program Posbindu PTM saya melihat ada 5 orang SDM untuk peleksanaan program Posbindu PTM saya rasa itu sudah cukup, dan melihat mereka bertugas dalam pelaksaan program Posbindu PTM saya rasa juga sudah sesuai kemampuan mereka. Hanya saja dalam pelaksanaan program Posbindu PTM tidak menetap untuk pelaksanaannya”. 
Journal of Healthcare Technology and Medicine Vol. 6 No. 2 Oktober 2020

Universitas Ubudiyah Indonesia

e-ISSN : 2615-109X

Berikut hasil wawancara saya dengan masyarakat dari kelurahan Aur yang rutin mengikuti program Posbindu PTM, yaitu dengan Ibu Ayuk. Berikut narasai Ibu Ayuk terkait SDM dalam pelaksanaan program Posbindu PTM :

“ Iya kalo yang saya lihat iya SDM sudah cukup, dan mereka selama pelaksanaan program Posbindu PTM pun sudah memiliki tugas masing-masing, kemampuan petugas dalam pelaksanaan program Posbindu PTM sudah baik namun masih perlu lagi peningkatan. Fasilitas dalam segi gedung masih belum ada yang khusus”.

Adapun hasil wawancara saya dengan Ibu Riri masyarakat dari kelurahan Sukaraja yang tidak rutin mengikuti program Posbindu PTM, berikut narasinya :

“ SDM dalam pelaksanaan program Posbindu PTM ini sudah cukup, tugas dalam pelaksanaan program Posbindu PTM sudah semau menjalankan, kemampuan dalam pelaksanaan program Posbindu PTM juga sudah bagus, hanya saja waktu yang buat saya jarang mengikuti program Posbindu PTM”.

Berikut hasil wawancara terakhir dengan Ibu Erwina selaku Kepala Puskesmas di Puskesmas Kampung Baru menyatakan kurangnya fasilitas gedung yang mendukung pelaksanaan program Posbindu PTM, adapun narasi Ibu Erwina sebagai berikut :

"SDM dalam program Posbindu PTM sudah mencukupi, hmmm dana dari puskesmas yang ada itu juga dana pemerintah juga sih, tetapi kalo dana dari dinas kesehatan belum ada. Hmm.. kalo sarana gedung itu belum ada yang khusus tetapi kalo alat sudah lengkap semua”.

“Wewenang? Sudah semua wewenang dibagi ratakan kepada semua SDM sudah semua bertanggungjawab dalam tugasnya hanya saja perlu peningkatan agar lebih baik lagi dalam pelaksanaan program Posbindu PTM”.

Dalam pelaksanaan program Posbindu PTM peran struktur sosial/sumber daya sangat mendukung pelaksanaan program Posbindu PTM, salah satunya menjadi SDM yang bertanggungjawab dan sukarelawan. Indikator keberhasilan dapat dijadikan sebagai pengukur keberhasilan variabel sumber daya, yaitu staf, informasi, wewenang, dan fasilitas dan alat yang mendukung. Staf dalam pelaksanaan program Posbindu PTM sudah cukup dalam pelaksanaan program Posbindu PTM. Informasi yang dalam pelaksanaan program Posbindu PTM sudah diterapkan dengan baik dan informasi mengenai kepatuhan dari pelaksana program Posbindu PTM sudah dipatuhi. Wewenang SDM dalam pelaksanaan program Posbindu PTM sudah 
Journal of Healthcare Technology and Medicine Vol. 6 No. 2 Oktober 2020

Universitas Ubudiyah Indonesia

e-ISSN : 2615-109X

terlaksana dengan baik. Fasilitas merupakan suatu kendala, dimana fasilitas gedung tidak tersedia secara khusus dalam pelaksanaan program Posbindu PTM, itu yang menjadi sebab utama pelaksanaan program Posbindu PTM kewalahan dalam mencari dan menentukan tempat dalam pelaksanaan program Posbindu PTM. Serta alat yang mendukung untuk pelaksanan program Posbindu PTM sudah lengkap disediakan. Dan terdapat dana dari Pemerintah dan tidak ada dari Dinas Kesehatan dalam pelaksanaan program Posbindu PTM.

Penelitian sebelumnya yang mendukung adanya pelaksanaan program Posbindu PTM yang merupakan salah satu peneliti di Puskesmas Srondol Kulon serta yang mendukung adanya pelaksanaan program Posbindu PTM dilaksanakan yaitu, mayoritas informan menyatakan bahwa ketersediaan jumlah staf/kader dalam pelaksanaan program posbindu PTM di wilayah kerja puskesmas sudah tercukupi.Dalam melaksanakan program posbindu PTM, Seluruh informan menyatakan bahwa sarana dan prasarana dapat menggunakan fasilitas yang sudah dimiliki lingkungan sekitar. Sumber dana dalam pelaksanaan program posbindu PTM di wilayah kerja puskesmas berasal dari swadana masyarakat atau iuran dari masyarakat yang dilakukan dalam setiap bulannya dan tidak ada dana dari pemerintah. (Irmawati et al., 2018)

\section{Peran Disposisi Dalam Implementasi Program Posbindu PTM}

Berdasarkan informasi dari hasil wawancara via chat wa dengan petugas Posbindu PTM yaitu seorang perawat di Puskesmas Kampung Baru menyatakan bahwa Disposisi dalam pelaksanaan program Posbindu PTM ini sudah baik dan sangat mendukung adanya pelaksanaan program Posbindu PTM. Berikut narasi dengan perawat (Penanggungjawab Posbindu PTM) tersebut :

“Iya kalo saya pribadi sangat mendukung adanya program Posbindu PTM ini, bukti saya mendukung adanya program Posbindu PTM ini saya datang tepat waktu untuk pelaksanaan program Posbindu PTM ini, dan alat-alat yang disediakan juga sangat mendukung berjalannya program Posbindu PTM ini. Sikap saya dala dan semua SDM dalam pelaksanaan program Posbindu PTM ini sudah sangat baik terhadap kelompok sasaran”.

Berdasarkan informasi yang didapat melalui wawancara via telfon dengan kader kelurahan Aur dengan Ibu Mimi menyatakan bahwa Disposisi dalam pelaksanaan program Posbindu PTM sangat mendukung sama dengan apa yang disampaikan oleh penanggungjawab program Posbindu PTM, berikut narasi dari kader tersebut : 
Journal of Healthcare Technology and Medicine Vol. 6 No. 2 Oktober 2020

Universitas Ubudiyah Indonesia

e-ISSN : 2615-109X

“Iya kalau dibilang sih siapa yang tidak mendukung adanya program Posbindu PTM ini, saya sangat mendukung dikarenakan saya tidak perlu repot-repot jauh ke puskesmas mau memantau kesehatan saya setiap bulan kan? Bukti saya mendukung saya mau bekerja jadi kader kesehatan dikelurahan ini dengan sukarelawan. Dan masalah sikap saya dan petugas lainnya sudah baik saya ras”.

Dan dari hasil wawancara saya dengan Ibu Melu sangat mendukung adanya program Posbindu PTM ini dikelurah Sukaraja, berikut narasi dari Ibu Melu selaku kader dari kelurahan Sukaraja tersaji dibawah ini :

“ Sikap saya iya bisa dibilang baiklah karena kami bekerja untuk masyarakat jadi kalo saya pribadi saja sikapnya tidak baik bagaimana bisa masyarakat akan nyaman nantinya, dan bagaimana masyarakat agar bertambah untuk mengikuti program Posbindu PTM. Dan adanya program Posbindu PTM ini sangat mendukung dikarenakan itu sayabersedia dipilih menjadi salah satu kader kesehatan yang sukarelawan dikelurahan Sukaraja ini”.

Berikut hasil wawancara dengan Bapak Tanjung sangat mendukung adanya program Posbindu PTM ini dikelurahan Aur tersebut. narasi dari Tokoh masyarakat dikelurahan Aur yang setiap bulannya rutin mengikuti program Posbindu PTM :

“Ahk.. kalo saya pribadi melihat sikap dari petugas semua sudah baik terhadap semua kelompok sasaran, dan masalah mendukung pasti saya dukunglah karena kan tidak perlu jauh-jauh lagi ke puskesmas untuk memantau kesehatan, dengan adanya program Posbindu PTM ini disinipun kita kan bisa memantau kesehatan. Salah satu bukti saya mendukung program Posbindu PTM ini dengan rutin hadirnya dalam setiap bulannya untuk mengikuti program Posbidnu PTM ”.

Berikut hasil wawancara saya dengan masyarakat dari kelurahan Aur yang rutin mengikuti program Posbindu PTM, yaitu dengan Ibu Ayuk yang sama persis jawabannya dengan Tokoh Masyarakat. Berikut narasai Ibu Ayuk terkait SDM dalam pelaksanaan program Posbindu PTM

“Ahk. kalo saya pribadi melihat sikap dari petugas seтиa sudah baik terhadap seтиa kelompok sasaran, dan masalah mendukung pasti saya dukunglah karena kan tidak perlu jauh-jauh lagi ke puskesmas untuk memantau kesehatan, dengan adanya program Posbindu PTM ini disinipun kita kan bisa memantau kesehatan. Salah satu 
Journal of Healthcare Technology and Medicine Vol. 6 No. 2 Oktober 2020

Universitas Ubudiyah Indonesia

e-ISSN : 2615-109X

bukti saya mendukung program ini dengan rutin hadirnya dalam setiap bulannya mengikuti program Posbidnu PTM inilah”.

Adapun hasil wawancara saya dengan Ibu Riri masyarakat dari kelurahan Sukaraja yang tidak rutin mengikuti program Posbindu PTM, berikut narasinya :

“ Saya merasa sikap dari petugas sudah baik itu bisa membuktikan dengan bertambahnya masyarakat yang hadir yang pernah saya lihat, saya jarangpun mengikuti program Posbindu PTM namun pas saya datang itu yang saya lihat. Dan untuk program ini saya pribadi sangat mendukug, dikarenakan tidak dengan saya semua bisa memantau kesehatan dengan setiap bulannya, saya pribadi kalo jadwal kerjaan saya tidak sama dengan pelaksanaan program Posbindu PTM ini saya selalu mengikutinya, hanya karena kadang bersamaannya makanya saya tidak rutin mengikutinya".

Berikut hasil wawancara terakhir dengan Ibu Erwina selaku Kepala Puskesmas di Puskesmas Kampung Baru menyatakan sangat mendukung adanya program Posbindu PTM dilaksanakan dalam setiap kelurahan, adapun narasi Ibu Erwina sebagai berikut :

“Saya rasa sikapnya penanggungjawab yang lebih tau tetapi saya rasa baik-baik saja sih, dan untuk adanya program Posbindu PTM ini saya sangat mendukung”.

Dalam pelaksanaan penelitian di Puskesmas Kampung Baru peran Disposisi sangatlah mendukung dalam pelaksanaan program Posbindu PTM, dimana salah satunya sebagian besar kelompok sasaran mau mengikuti pelaksaan program Posbindu PTM rutin setiap bulannya, itu dikarenakan sikap dari petugas yang baik terhadap kelompok sasaran dan kelompok sasaran juga sangatlah mendukung adanya pelaksanaan program Posbindu PTM dilaksanakan. Adapun pernyataan kelompok sasaran tidak ikut serta dalam pelaksanaan program Posbindu PTM dikarenakan adanya kesibukan seperti bekerja yang bersamaan dengan jadwal pelaksanaan program Posbindu PTM. Adapun sikap yang baik diterapkan oleh petugas tetapi masih perlu adanya peningkatan agar semakin banyaknya kelompok sasaran yang datang dan berjalannya program Posbindu PTM dengan baik.

Bedasarkan hasil penelitian yang dilakukan seluruh informan dinyatakan kecenderungan sikap untuk mendukung pelaksanaan program dengan dilakukannya beberapa perbaikan sehingga tujuan program Posbindu PTM dikepulauan anambas dapat tercapai. Dalam hasil penelitiannya, Rusdiyanti (2018) mengungkapkan bahwa peran dan sikap kadar memiliki korelasi terhadap ke aktifan kunjungan masyarakat, sikap kadar yang mendukung 
Journal of Healthcare Technology and Medicine Vol. 6 No. 2 Oktober 2020

Universitas Ubudiyah Indonesia

e-ISSN : 2615-109X

akan berpengaruh terhadap maksimalnya uapaya dan peran yang dilakukan dalam pelaksaaan program Posbindu PTM. (Pratama et al., 2020)

\section{Peran Struktur Birokrasi Dalam Implementasi Program Posbndu PTM}

Berdasarkan informasi dari hasil wawancara via chat wa dengan petugas Posbindu PTM yaitu seorang perawat di Puskesmas Kampung Baru menyatakan bahwa Struktur Birokrasi dalam pelaksanaan program Posbindu PTM ini sudah baik dan sesuai ketentuan. Berikut narasi dengan perawat (Penanggungjawab Posbindu PTM) tersebut :

“ Ohh kalo untuk penyebaran tanggungjawab sudah diberikan semua tanggungjawab dalam pelaksanaan program Posbindu PTM, dan untuk SOP sudah sesuai dengan ketentuan salah satu contoh dalam pelaksanaan program Posbindu PTM adanya 5 meja yang mendukung pelaksanaan program Posbindu PTM”.

Berikut hasil wawancara terakhir dengan Ibu Erwina selaku Kepala Puskesmas di Puskesmas Kampung Baru menyatakan adanya SOP dalam program Posbindu PTM, adapun narasi Ibu Erwina sebagai berikut :

“ Iya kalo penyebaran tanggungjawab sudah disebarkan dan disaat pelaksanaan program Posbindu PTM semua sudah bekerja sesuai dengan tanggungjawab masing-masing, dan untuk SOP yang mendukung pasti ada iya kamu minta sama penanggungjawab program Posbindu PTM. SOP pengukuran kadar gula darah ada SOP nya, pengukuran kadar lemak ada juga SOP nya, kamu minta saja iya sama penanggungjawab program Posbindu PTM"

Adapun peran struktur birokrasi dalam pelaksanaan program Posbindu PTM sangat mendukung, namun petugas dan penanggungjawab program Posbindu PTM hanya mengungkapkan adanya Standar Operasional Prosedur (SOP) yang mendukung adanya program Posbindu PTM. Akan tetapi peneliti meminta bukti Standar Operasional Prosedur (SOP) nya penanggungjawab program hanya memberikan salah satu contohnya yaitu diterapkannya 5 meja dalam pelaksanaan program Posbindu PTM. Dalam pembagian dan penanggungjawaban program semua petugas sudah menerapkan tanggungjawab yang sesuai dengan apa yang telah diberikan dan konsisten dalam tanggungjawab masing-masing serta bekerja dengan tugas maisng-masing.

Dari penelitian sebelumnya SOP khusus program Posbindu PTM di wilayah kerja puskesmas Bulu Lor belum dibuat. Struktur organisasi sudah dibentuk, koordinasi antar 
Journal of Healthcare Technology and Medicine Vol. 6 No. 2 Oktober 2020

Universitas Ubudiyah Indonesia

e-ISSN : 2615-109X

pelaksana cukup baik. Pelaporan dilakukan secara berjenjang, serta pembagian tugas yang sudah diterapkan. ( Ratnasari, 2019)

\section{KESIMPULAN}

Pelaksanaan program Posbindu PTM di Puskesmas Kampung Baru dapat dikatakan belum berjalan dengan baik setiap 1 bulan sekali di masing-masing kelurahan yang sudah ditetapkan. Adapun kendala dalam segi Komunikasi, yaitu kurangnya konsisten dengan waktu mengakibatkan petugas dan masyarakat sering mengundurkan waktu dalam pelaksanaan program Posbindu PTM. Sumber Daya indikator keberhasilan dapat dilihat dari staf, informasi, wewenang dan fasilitas. Yang menjadi kendala dalam Sumber Daya adalah Fasilitas Gedung dalam program Posbindu PTM masih belum ada sehingga dalam pelaksanaan program Posbindu PTM disetiap bulannya selalu berganti gedungnya/tempatnya. Disposisi sudah mendukung keberhasilan program Posbindu PTM di Puskesmas Kampung Baru, dilihat dari sikap dan dukungan petugas serta masyarakat dalam pelaksanaan program Posbindu PTM. Struktur Birokrasi sudah berjalan sesuai dengan yang ditentukan, salah satu contohnya adanya Standar Operasional Prosedur (SOP) dalam pelaksanaan program Posbindu PTM. Seperti, 5 meja dalam pelaksanaan program Posbindu PTM, dan pembagian tanggungjawab sudah diberikan dan dalam pelaksanaan program Posbindu PTM sudah dijalankan sesuai dengan tanggungjawab masing-masing. (Damayanti, 2018)

\section{SARAN}

Petugas pelaksana program Posbindu PTM lebih meningkatkan sosialisasi mengenai Posbindu PTM. Petugas dari Puskesmas Kampung Baru semakin rajin untuk memberi arahan kepada kader-kader agar kader-kader semakin baik dalam melaksanakan program Posbindu PTM. Kader, petugas dan masyarakat semakin konsisten dengan waktu agar pelaksanaan program Posbindu PTM sesuai dengan jadwal yang telah ditetapkan. Kepala Puskesmas dan Penanggungjawab program Posbindu PTM agar menyediakan fasilitas gedung untuk pelaksanaan program Posbindu PTM, agar masyarakat tidak bingung untuk mengikuti program Posbindu PTM disetiap bulannya. Masyarakat agar lebih antusias dan berpartisipasi lagi dalam pelaksaan program Posbindu PTM sehingga mengurangi peningkatan penyakit tidak menular seperti Hipertensi, Diabetes Mellitus dan lain-lain dan mendorong suksesnya program Posbindu PTM. 
Journal of Healthcare Technology and Medicine Vol. 6 No. 2 Oktober 2020

Universitas Ubudiyah Indonesia

e-ISSN : 2615-109X

\section{DAFTAR PUSTAKA}

Bachri, B. S., Pendidikan, T., \& Pendidikan, F. I. (2010). Meyakinkan Validitas Data Melalui Triangulasi Pada Penelitian Kualitatif. 10, 62.

Damayanti, F. A. (2018). Analisis Pelaksanaan Program Pos Pembinaan Terpadu Penyakit Tidak Menular ( Posbindu PTM ) di Puskesmas Glugur Darat.

Efrida, Nur, N. N., Mikrobiologi, B., Kedokteran, F., \& Lampung, U. (2016). Faktor Risiko Perilaku Penyakit Tidak Menular. 5, 7.

Febrianti, P. (2016). Implementasi Pelaksanaan Pos Pembinaan Terpadu Penyakit Tidak Menular ( Posbindu PTM ) di Pusksmas Pucang Sewu Kota Surabaya. 7.

Laporan Tahunan Kp. Baru (2019). (p. 64).

Nasruddin, N. R. (2017). Faktor-faktor Yang Mempengaruhi Pemanfaatan Pos Pembinaan Terpadu Penyakit Tidak Menular (Posbindu PTM) di Wilayah Kerja Puskesmas Ballaparang Kota Makassar. 5, 136.

Pranandari, A. F. (2017). Analisis Implementasi Prgram Pos PembinaanTerpadu Penyakit Tidak Menular(Posbindu PTM)di Kecamatan Banguntapan Kabupaten Bantul. 5.

Primiyani, Y. (2018). Artikel Penelitian Analisis Pelaksanaan Program Pos Pembinaan Terpadu Penyakit Tidak Menular di Kota Solok. 8(2), 399-406.

Putri, R. E., Studi, P., Masyarakat, K., Masyarakat, F. K., Jambi, U., Ilmu, D., Masyarakat, K., Masyarakat, F. K., \& Jambi, U. (2018). Evaluasi Proses Implementasi Posbindu PTM diWilayah Kerja Puskesmas Simpang Sungai Duren Kecamatan Jambi Luar Kota Kabupaten Muaro Jambi. 2(1), 12-27.

Rahmat. (2009). Jurnal-Penelitian-Kualitatif.pdf (p. 8).

Refiola Irmawati, Wigati, A. (2018). Analisis Pelaksanaan Program Pos Pembinaan Terpadu Penyakit Tidak Menular di Wilayah Kerja Puskesmas Srondol Kulon, Kota Semarang (Studi Kasus di RW 13, Kecamatan Srondol Wetan, Kelurahan Banyumanik). 6.

Sicilia, G., Sari, F., Dewi, T., Padmawati, R. S., Ilmu, D., Masyarakat, K., Kedokteran, F., Masyarakat, K., \& Mada, U. G. (2018). Evaluasi Kualitatif Program Pengendalian Penyakit Tidak Menular Berbasis Posbindu di Wilayah Kerja Puskesmas Muara Bungo i. 07(02), 88-94.

Teknis, P. (2012). Penyakit Tidak Menular.

Umayana, Cahyati (2015). Dukungan Keluarga Dan Tokoh Masyarakat Terhadap Keaktifan Penduduk Ke Posbindu Penyakit Tidak Menular. 11(1), 96-101.

Ika, A. R. (2019). Analisis Implementasi Program Pos Pembinaan Terpadu Penyakit Tidak Menular (Posbindu PTM) Di Wilayah Kerja Puskesmas Bulu Lor Kota Semarang. (p)115.

Pratama, Susanto, Warella (2020). Program Pos Pembinaan Terpadu Penyakit Tidak Menular di Daerah Kepulauan. 4 (2) (p)10 